\title{
Comment on "Facile Deposition of Ultrafine Silver Particles on Silicon Surface Not Submerged in Precursor Solutions for Applications in Antireflective Layer"
}

\author{
Joondong Kim and Hyunki Kim \\ Department of Electrical Engineering, Incheon National University, Incheon 406772, Republic of Korea \\ Correspondence should be addressed to Joondong Kim; joonkim@incheon.ac.kr
}

Received 31 May 2015; Accepted 11 June 2015

Academic Editor: Yanbao Zhao

Copyright (c) 2015 J. Kim and H. Kim. This is an open access article distributed under the Creative Commons Attribution License, which permits unrestricted use, distribution, and reproduction in any medium, provided the original work is properly cited.

We have investigated the recent research article, titled "Facile Deposition of Ultrafine Silver Particles on Silicon Surface Not Submerged in Precursor Solutions for Applications in Antireflective Layer" by Jiang et al. [1]. The authors systematically organized the silver nanoparticles on Si substrates, which is a very effective approach to reduce the reflection by forming $\mathrm{Si}$ porous structures. The ultrafine porous $\mathrm{Si}$ showed significantly suppressed reflection about less than $5 \%$ for broad wavelengths. This result bears a high potential of Si photoelectric devices, including photodetectors and solar cells.

Nanostructures have a promising potential to enlarge the surface area, at a fixed volume, and thus simultaneously increase the light-reactive region of a solar cell. Additionally, the nanoscale structure is also efficient at reducing the light reflection of the incident light [2-4]. To have the optical advantage (less reflection) of Si structures is a significantly important benefit for the improvement of electrical aspects of devices. Ideal photoelectric devices can improve the performances due to the enhanced optical absorption.

Practically, however, the geometry tailoring of lightabsorber readily causes recombination losses, which is inevitable concern for the most nanoscale patterned photoelectric devices. Researchers reported "zero" (or near zero) reflector by using various nanoscale entities. However, up to date, this state-of-the-art nanoscale zero reflector is not much effective to improve the practical solar cell performances. This is because of the overweighted design for optical aspects of nanoscale structured solar cells [5-9]. It also clearly suggests that there exists a discrepancy between the optical advantage and the electrical performances.

We expect the practical device performances from the silver nanoparticle-assisted $\mathrm{Si}$ nanostructures, which will provide a broad readership to researchers for the potential of ultrafine porous $\mathrm{Si}$ for photoelectric applications.

Otherwise, we may think about how we can realize the optical benefits of light management into electrically improved performances. This important issue can be resolved by using a conductive transparent material as multifunctional purpose. As an example, we can apply electrical conductor, such as indium-tin-oxide (ITO) or aluminum-doped $\mathrm{ZnO}$ (AZO), to the refractive-index matching entity. These transparent conducting materials may spontaneously reduce the electrical recombination loss by contributing to the transport of photogenerated carriers [3,4]. Figure 1 is one of possible schemes of multifunctional nanostructured photoelectric devices. 

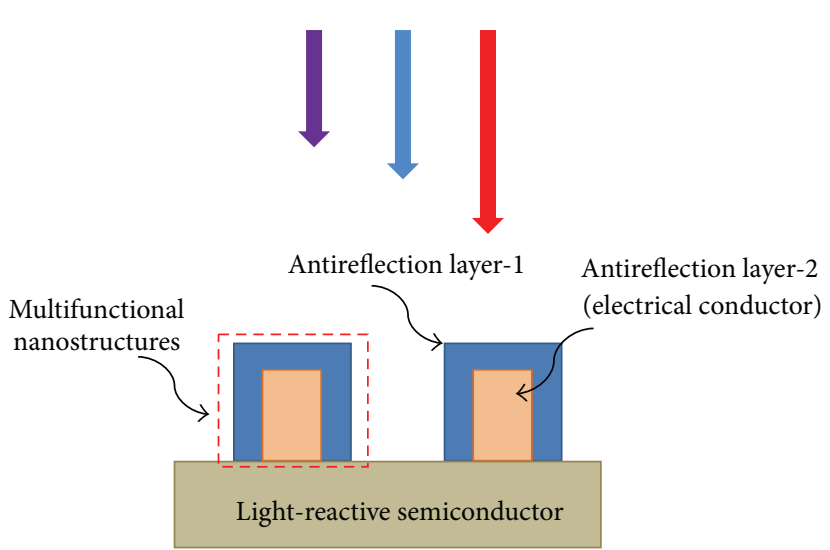

FIGURE 1: Suggested scheme: multifunctional designs of front structures for high-efficient nanoscale patterned photoelectric devices.

\section{Conflict of Interests}

The authors declare that there is no conflict of interests regarding commercial or financial relationships.

\section{References}

[1] B. Jiang, M. Li, D. Song, Y. Li, and T. Mwenya, "Facile deposition of ultrafine silver particles on silicon surface not submerged in precursor solutions for applications in antireflective layer," Journal of Nanomaterials, vol. 2014, Article ID 351360, 6 pages, 2014.

[2] J. Kim, M. D. Kumar, J.-H. Yun et al., "Transparent conductorembedding nanolens for Si solar cells," Applied Physics Letters, vol. 106, no. 15, Article ID 151904, 2015.

[3] J. Kim, J. Yun, H. Kim et al., "Transparent conductorembedding nanocones for selective emitters: optical and electrical improvements of Si solar cells," Scientific Reports, vol. 5, article 9256, 2015.

[4] J. H. Yun, E. Lee, H. H. Park et al., "Incident light adjustable solar cell by periodic nanolens architecture," Scientific Reports, vol. 4, article 6879, 2014.

[5] H.-D. Um, K.-T. Park, J.-Y. Jung et al., "Incorporation of a selfaligned selective emitter to realize highly efficient (12.8\%) Si nanowire solar cells," Nanoscale, vol. 6, no. 10, pp. 5193-5199, 2014.

[6] F. Priolo, T. Gregorkiewicz, M. Galli, and T. F. Krauss, "Silicon nanostructures for photonics and photovoltaics," Nature Nanotechnology, vol. 9, no. 1, pp. 19-32, 2014.

[7] M. M. Adachi, M. P. Anantram, and K. S. Karim, "Core-shell silicon nanowire solar cells," Scientific Reports, vol. 3, article 1546, 2013.

[8] Y. Cho, M. Gwon, H. H. Park, J. Kim, and D. W. Kim, "Wafer-scale nanoconical frustum array crystalline silicon solar cells: promising candidates for ultrathin device applications," Nanoscale, vol. 6, no. 16, pp. 9568-9573, 2014.

[9] J. Kim, S. Park, M. Ju, and C. Jeong, "Characteristics of carrier collection of nanopillar-patterned silicon solar cells," Journal of Nanoscience and Nanotechnology, vol. 15, no. 3, pp. 2400-2403, 2015. 

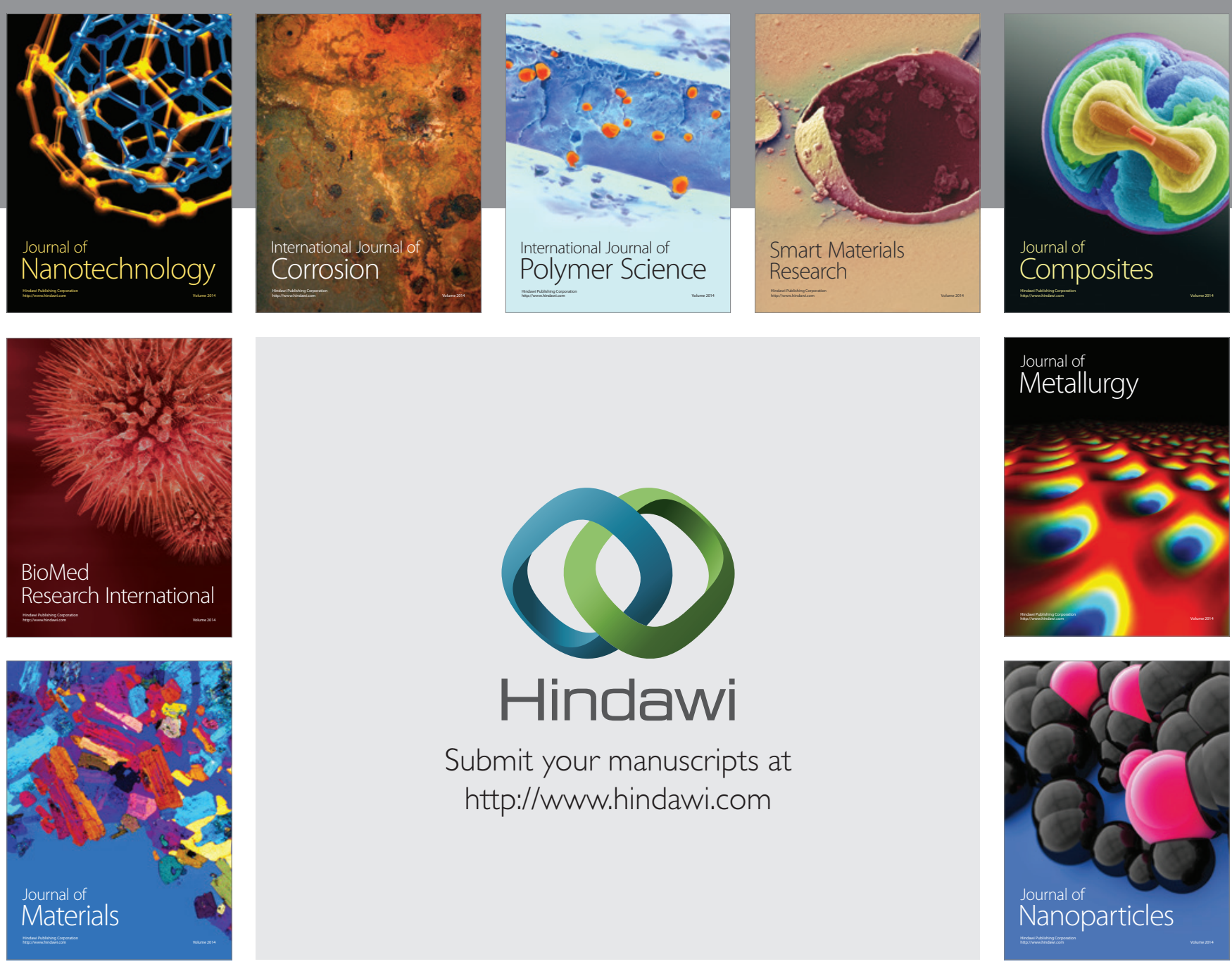

Submit your manuscripts at http://www.hindawi.com
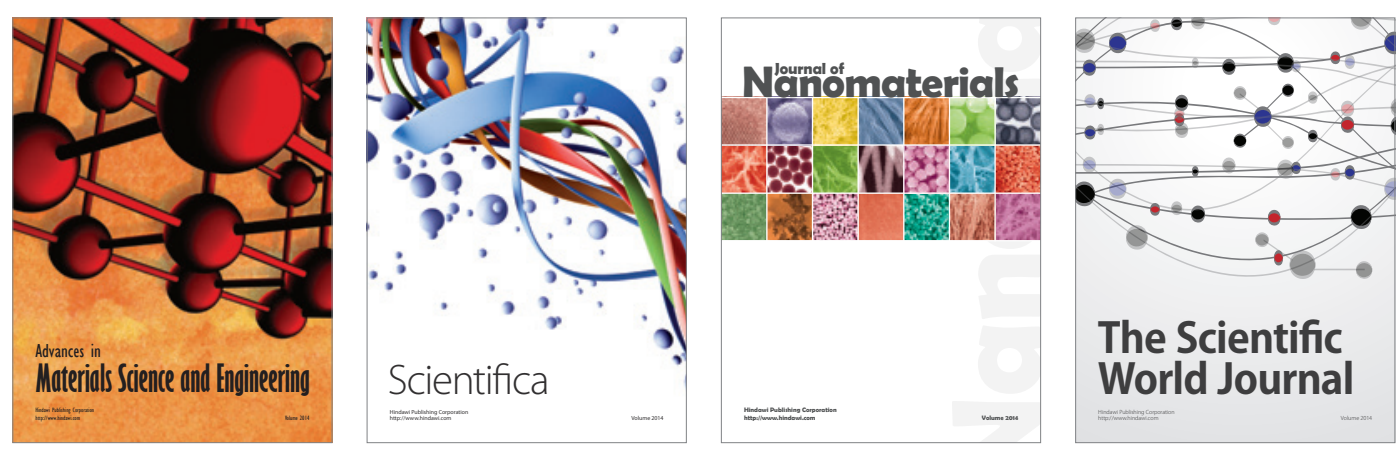

\section{The Scientific World Journal}
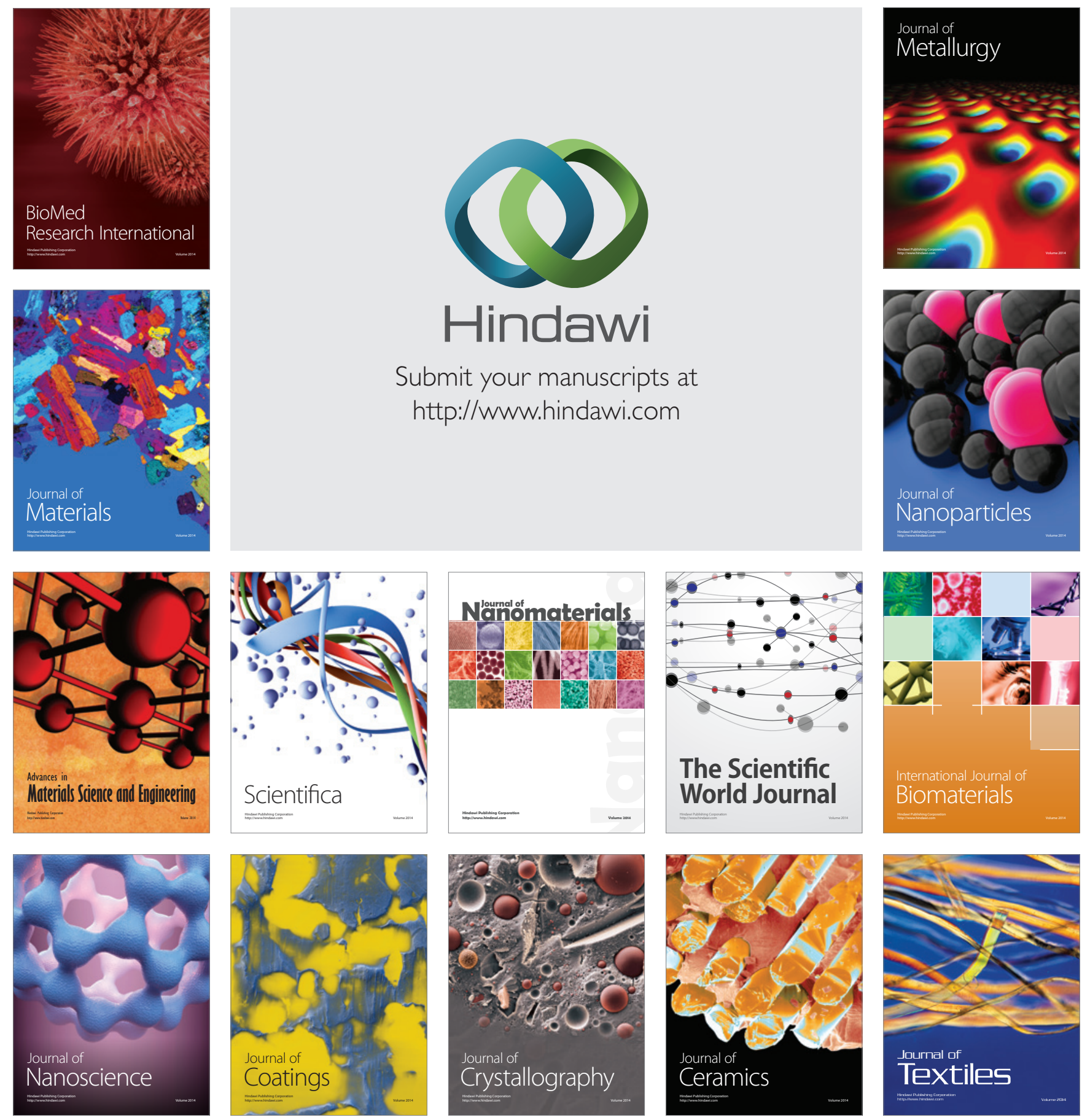